\title{
AN INVESTIGATION OF SERUM LIPIDS AND LIPOPROTEINS BY PAPER ELECTROPHORESIS
}

\author{
BY \\ W. G. DANGERFIELD AND E. B. SMITH \\ From the Department of Pathology, St. Bartholomew's Hospital, London
}

(RECEIVED FOR PUBLICATION JANUARY 1, 1955)

In view of the importance now attached to them it is remarkable that the lipoproteins of human serum received so little attention from early workers. In 1929 Machboeuf isolated an alpha-lipoprotein from horse serum and in 1935 McFarlane, in the course of ultracentrifuge studies of human serum, discovered the "X-Fraction" which was later shown by Pedersen to be beta-lipoprotein. The development of large-scale ethanol fractionation of human plasma pools led to a much better understanding of the lipoproteins, particularly betalipoprotein (Oncley, Gurd, and Melin, 1950). Recently there has been evidence that the lipids or lipoproteins are changed in some manner in atherosclerosis, and this has led to more extensive studies by fractionation and by ultracentrifugation. Paper electrophoresis provides an alternative and simpler method of investigation which needs only inexpensive apparatus and has the additional advantage of requiring a very small specimen of blood. After electrophoresis the strips can be cut lengthwise and stained by various methods to show the relative position of different components. Swahn (1952) and Kunkel and Slater (1952) have already reported the results of the electrophoresis of lipoproteins in a few sera; we have examined the lipid pattern in some 400 samples of serum and have distinguished from three to five components. An attempt has been made to correlate the patterns with the clinical condition and to identify some of the components on the paper.

\section{Techniques}

Electrophoresis.-The strips are normally run suspended over a bar in the apparatus described by Flynn and de Mayo (1951). The type of paper, and the amount of serum applied, depends on the particular investigation. For serum proteins we use Whatman No. 1 with $0.007 \mathrm{ml}$. of serum per inch; lipoprotein patterns that are to be scanned are run on Whatman No. 1 with $0.02 \mathrm{ml}$. of serum per inch; lipoprotein patterns for visual inspection are run on Whatman No. 100 or 3MM paper, with $0.04 \mathrm{ml}$. of serum per inch. For all strips barbiturate buffer, $p \mathrm{H} 8.6$, ionic strength 0.05 , is used. Direct comparison of the position of bands is never made between separate strips, as even adiacent strips may not be quite comparable. When protein-, lipid-, and cholesterol-staining bands are to be compared one wide strip is cut lengthwise after ruling clear marker lines to allow for exact positioning of the different pieces.

Staining Methods.-The following give good results:

Proteins.-The stain is $0.5 \%$ light green S.F. (Colour Index No. 669) dissolved in water containing $25 \%$ ethanol and $5 \%$ glacial acetic acid.

The strips are stained for 10 minutes, at room temperature, then washed in $2 \%$ acetic acid in tap water until the background is colourless.

Lipids.-The stain is a saturated solution of sudan black in $55 \%$ alcohol which has been matured for a few days and filtered before use.

The strips are stained for 30 minutes at room temperature, rinsed quickly in $50 \%$ alcohol, then washed out thoroughly in $40 \%$ alcohol. The background never becomes absolutely colourless, but in $\mathbf{4 0} \%$ alcohol very prolonged washing does not seem to reduce the intensity of colour in the actual lipid bands.

Cholesterol.-The Liebermann reaction is used, the amount of chloroform being greatly reduced to prevent the very soluble coloured product diffusing too rapidly.

Reagent.-Acetic anhydride, $8 \mathrm{ml}$., and $1 \mathrm{ml}$. chloroform are mixed, then $2 \mathrm{ml}$. concentrated sulphuric acid added drop-wise with constant cooling and mixing.

Method.-The reagent proved to be unsuitable for spraying because it takes up moisture from the atmosphere and is extremely unpleasant to handle. A layer of the reagent, approximately the size of the paper, is spread evenly in the bottom of a glass dish. The paper is then laid in it, and the lid put on while the blue or green colour develops; about five minutes gives maximum colour development. If the strip has to be handled it can be rapidly washed in ether and blotted, but moisture from the atmosphere soon causes the colour to fade. With practice it becomes easy to apply the right amount of reagent so that the paper is thoroughly wetted but there is no surplus. The reaction is given by both free and esterified cholesterol. The free cholesterol reacts instantaneously, but with the esters it is one or two minutes before the colour appears. 
Other Staining Methods.-Iodine vapour, dichromate and haematein (Hack, 1953), and osmium tetroxide were used in an attempt to distinguish between cholesterol, fat, and phospholipid. It was found that both the iodine vapour and the dichromate and haematein stained the protein as intensely as the lipid, and that osmium tetroxide stained all lipids without discrimination.

Extraction of Strips with Organic Solvents.-The lipids can be differentiated to some extent by extraction with organic solvents after electrophoresis. Ethanol was found to be the most useful solvent giving satisfactory removal of neutral fat and cholesterol. After electrophoresis the strip is put into a large stoppered boiling tube almost filled with ethanol, and shaken gently for two, four, or six minutes. Four minutes appears to be the optimum time, the pattern not changing appreciably on longer washing. The strip is then stained together with the unextracted portion.

Extraction of Serum with Ether.-Serum, $1 \mathrm{ml}$., was extracted with three successive $1-\mathrm{ml}$. portions of ether, either frozen to $-23^{\circ} \mathrm{C}$. or at $0^{\circ} \mathrm{C}$. The serum and ether were kept well mixed for 10 minutes, allowed to separate, and the ether pipetted off. The extraction was almost complete at both temperatures.

Storage of Serum.-The serum can be stored for about four days at $4^{\circ} \mathrm{C}$. without the fat pattern changing. Freezing at $-10^{\circ} \mathrm{C}$. causes no change in the pattern, and several sera have been stored in this state for many months without deterioration.

\section{Results}

General Description of Lipid Patterns.-There are two black-staining areas which we have called the alpha-lipid and beta-lipid zones. The alphalipid zone is level with the albumin and alpha $a_{1}$ globulin of the protein pattern, and consists of two or three overlapping bands. The beta-lipid zone extends from the line of application to a position between the alpha $a_{2}$ - and beta-globulin and usually contains three components which vary considerably in their relative intensities.

A detailed description of the individual components follows, starting at the line of application or origin, marked $\mathrm{O}$ in Fig. 1.

Beta-lipid Zone.-The lipid deposits at the origin and in the trail.

Normal sera give a faintly staining area extending from the line of application up to the beta-lipoprotein band; at the back it is sharply defined by the boundary of the area wetted during application of the serum, but in front the staining merges into the beta-lipoprotein band. With lipaemic sera this area is stained more intensely than usual; in the alcohol-extracted strips it is practically unstained. These deposits contain little cholesterol or phospholipid, and probably consist largely of neutral fat.

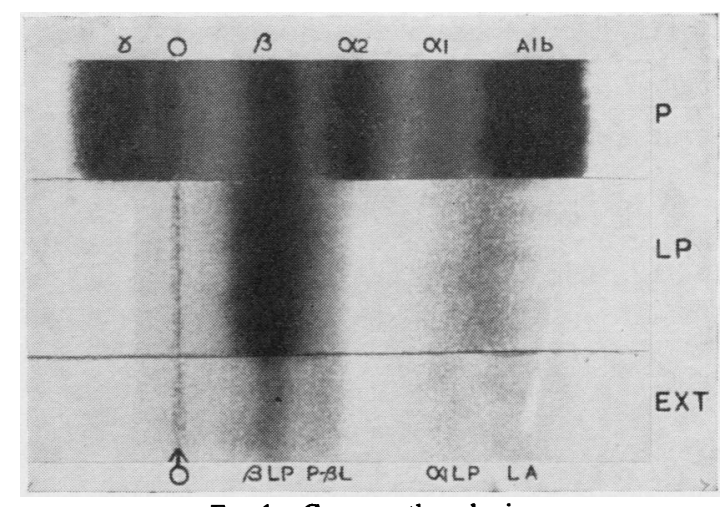

FIG. 1.-Coronary thrombosis.

$\mathbf{P}=$ protein, $\mathbf{L P}=$ lipoprotein, $\mathbf{E X T}=$ lipid in alcohol-extracted strip.

Beta-lipoprotein is an intense and sharply defined band level with the beta-globulin of the protein pattern which contains the bulk of the cholesterol and is also rich in phospholipid. It is greatly reduced by extraction with alcohol, leaving only a faint residual band.

With some sera the staining extends ahead of the beta-lipoprotein and appears to be due to an additional band which is partially obscured by the betalipoprotein. In the alcohol-extracted strips the beta-lipoprotein is greatly reduced, but this " prebeta-lipid " is virtually unchanged and may appear as a distinct band. It is a prominent feature of the nephrotic pattern, and occurs frequently in coronary thrombosis.

Alpha-lipid Zone.-This consists of two or three overlapping bands which sometimes show slightly differing shades. The chief component, the alphalipoprotein, lies just behind the albumin and may be slightly brownish. In front of it level with the albumin is a slightly bluish band, which we ascribe to "lipalbumin." Sometimes there is another faint bluish band behind the alpha-lipoprotein. Alcohol removes most of the alpha-lipoprotein but leaves the lipalbumin so that the extracted strip shows a lipalbumin band and in some cases a faint band level with alpha ${ }_{1}$-globulin (Figs. 1, 5).

Gamma-lipoprotein.-In a few cases pathological sera with a very high gamma-globulin level show a faint band of black staining level with the gammaglobulin which may be " gamma-lipoprotein."

Ether-extracted Serum.-Extraction of the serum with ether before electrophoresis makes no appreciable change in the protein pattern but removes almost all the lipid, although there is sometimes very faint staining in the alpha ${ }_{2}$-globulin and albumin regions. Incomplete extraction may leave a deposit of lipid at the origin and in the trail. 
Position of Cholesterol.-In normal sera, and in many with raised cholesterol, the Liebermann reaction shows the cholesterol of the beta-lipid zone to be limited to the narrow beta-lipoprotein band. However, in some cases of hyperlipaemia and of nephrosis with very high cholesterol and lipaemic sera there is in addition to the beta lipoprotein band a faint colour in the trail and prebeta-lipid (Fig. 2). By using a double quantity of serum a trace of cholesterol can be detected in the alpha-lipoprotein.

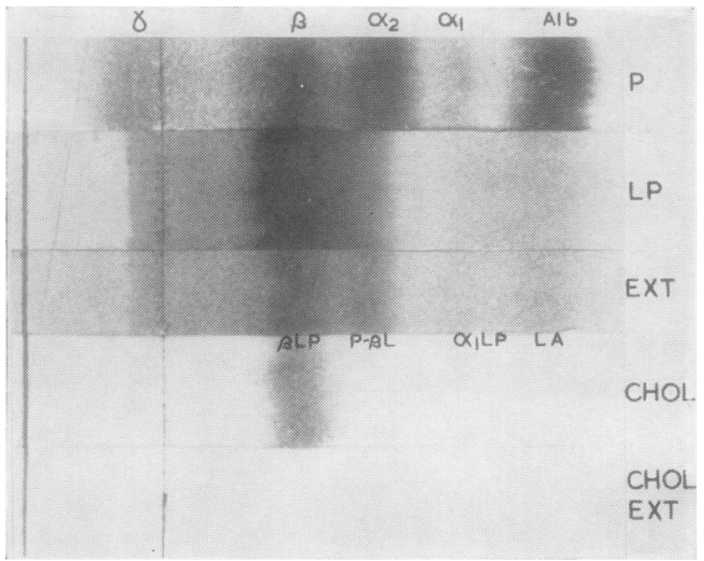

FIG. 2.-Nephrosis showing cholesterol distribution.

Position of Neutral Fat.-Four volunteers (one a diabetic) were given a fatty meal containing $80 \mathrm{~g}$. of butter fat and the serum examined immediately before and three hours after taking the meal. In all cases the post-prandial serum showed some degree of lipaemia, and in three cases the black stain at the origin was considerably intensified.

Position of Phosphorus.-The sera of patients with polycythaemia were examined by electrophoresis 44-48 hours after receiving radioactive sodium phosphate $\left.{ }^{32} \mathrm{P}\right)$, and the position of ${ }^{32} \mathrm{P}$ in the strip was determined by autoradiography (Fig. 3). The distribution of phosphorus closely resembled the distribution of sudan black staining. The highest concentration was level with the betalipoprotein band. The alpha-lipid bands, particularly the lipalbumin, were relatively rich in phosphorus and there were small concentrations in the trail and in the pre-beta-lipid. A band due to inorganic phosphate was present a considerable distance in front of the albumin. Alcohol extraction removed the bulk of the phosphorus from all components of the beta-lipid zone, but left that in the alpha-lipid zone almost unchanged.

Normal Serum Pattern.-The darkest part of the pattern (Fig. 4) is the beta-liproprotein band which

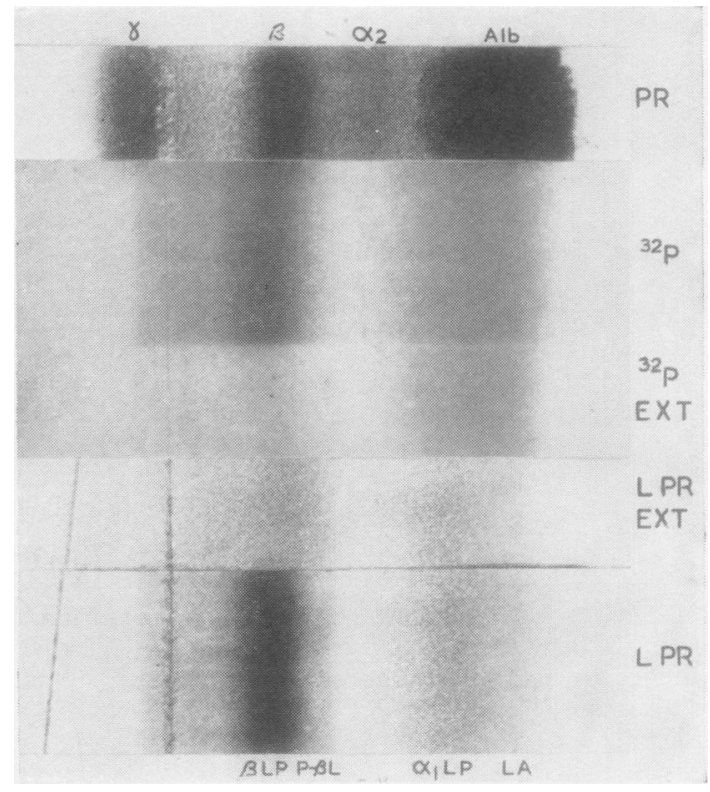

Fig. 3.-Phosphorus distribution.

is narrow and well defined; the alpha-lipid bands stain less darkly, but are considerably darker than the fat deposits at the origin or in the trail. The majority of normal sera have no pre-beta-lipid.

Nephrotic Syndrome.-Very characteristic changes in the serum protein and lipoprotein patterns occur in the nephrotic syndrome. The protein changes in the serum are well known; the albumin is always low, often very low, the alpha ${ }_{2}$-globulin is much increased, and in severe cases gamma-globulin and beta-globulin are reduced. The urinary proteins tend to be complementary to the serum; appreciable concentrations of albumin, alpha $a_{1}$, beta- and gamma-globulins are present but very little alpha $2^{-}$ globulin.

The lipid pattern of the serum (Figs. 2, 5, and 6) shows dense staining throughout the beta-lipid

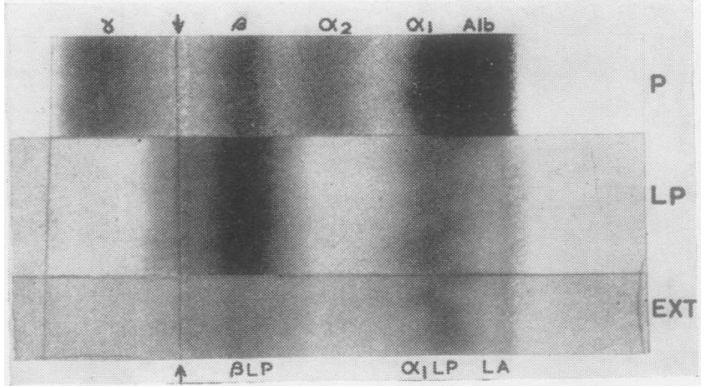

Fig. 4.-Normal serum. 


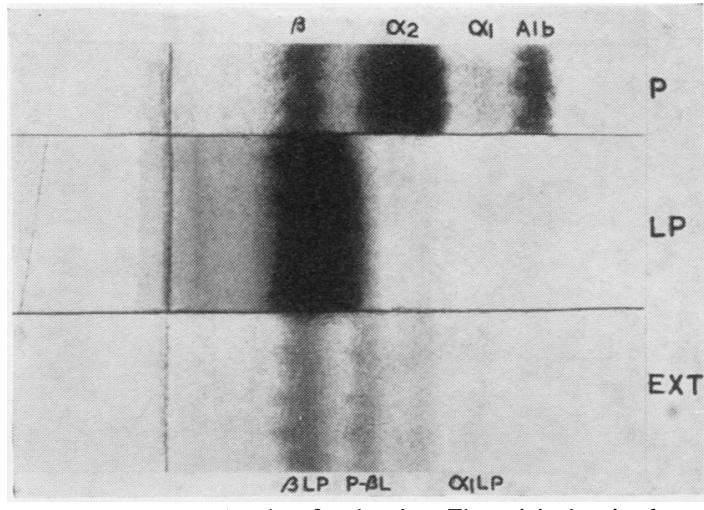

FIG. 5.-Nephrosis showing five bands. The original strip showed five bands, but two ( $a_{1}$ lipoprotein and lipalbumin) do not show in reproduction.

zone, all components being increased. A characteristic feature is the dense and wide pre-beta-lipid band which invariably extends to the rear of the alpha $_{2}$-globulin and in extreme cases extends to its leading edge. In the alcohol-extracted strips the beta-lipoprotein band is greatly reduced leaving only a faint residual band, whereas the pre-beta-lipid is only slightly reduced in intensity. In a few cases with a very high alpha $a_{2}$-globulin an additional faint band is seen corresponding in position with the alpha ${ }_{2}$-globulin (Fig. 5).

The fat deposits at the origin and in the trail are also increased and vary with the degree of lipaemia. The cholesterol is increased but it is still largely confined to the beta-lipoprotein band except in very lipaemic sera where a small amount is found in the trail and pre-beta-lipid. In contrast all components of the alpha-lipid zone are diminished and in severe cases are undetectable. Extraction of the serum with ether removes practically all the lipid, but leaves the protein pattern virtually unchanged.

Diabetes.-The patterns found in diabetes are varied; some are normal, some show a moderate

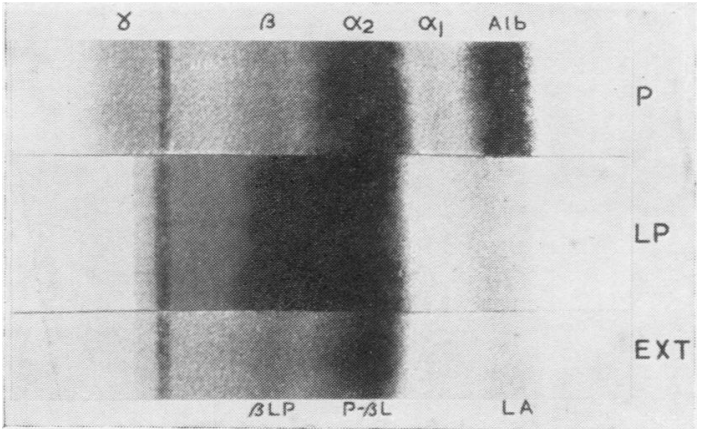

Fig. 6.-Nephrosis showing usual pattern.

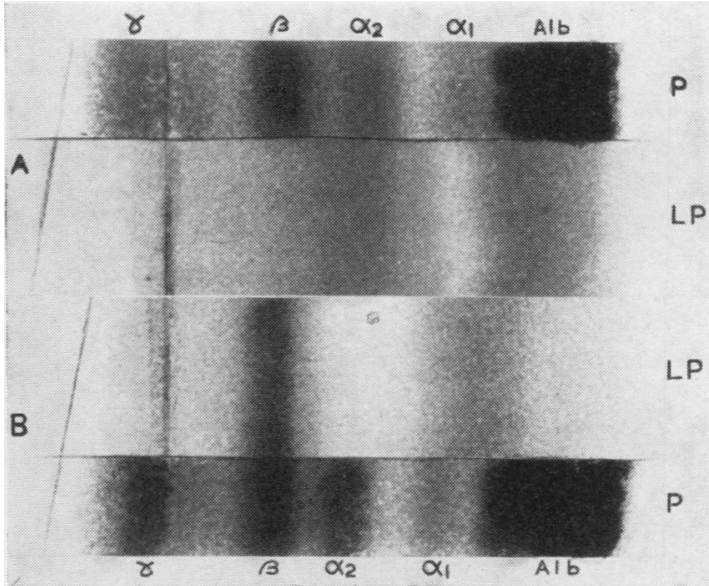

FIG. 7.-Diabetes.

pre-beta-lipid, and a few cases show a marked pre-beta-lipid extending to the front of the alpha $_{2}$ globulin. So far we have not found any clear correlation between the type of pattern and the clinical findings. In two cases of ketosis and coma the lipid front was swept forward, ahead of the alpha $a_{2}$-globulin; on recovery the patterns returned to normal. Fig. 7A shows the serum of a patient with severe ketosis, almost in coma, and Fig. 7B his serum taken 20 hours later, when he had almost recovered.

Myxoedema.-The beta-lipoprotein band is denser than usual, as might be expected from the increased serum cholesterol, and is often very sharply defined. Usually there is no increase in the neutral fat deposits and the pre-beta-lipid band occurs only in a few cases (Fig. 8).

Xanthomatosis and Idiopathic Hyperlipaemia.Two types of pattern are obtained in these conditions, one given by patients with hypercholesterolaemic xanthomatosis, and the other by patients with essential hyperlipaemia. In the former condition the serum is clear and the pattern obtained (Fig. 9A) is similar to that of myxoedema, with a very dense beta-lipoprotein band but no excess

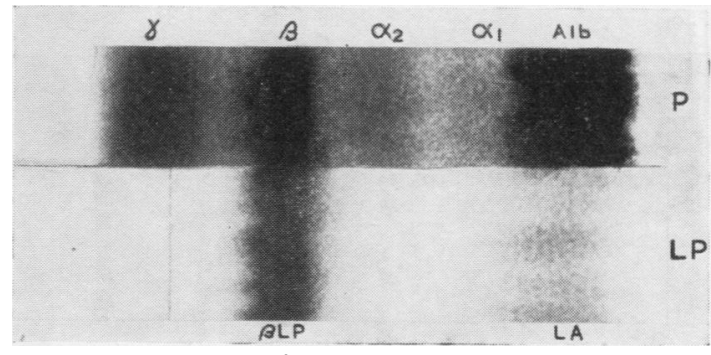

Fig. 8.-Myxoedema. 


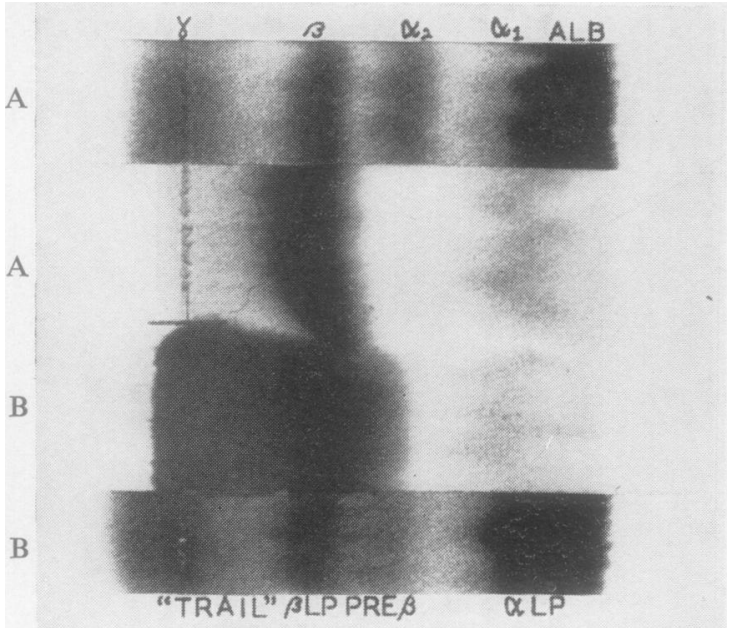

FiG. 9.-Xanthomatosis: A. Hypercholesterolaemia. B. Hyperlipaemia.

neutral fat or pre-beta-lipid. In the two cases of the latter condition we investigated the serum was very turbid, like milk, and gave a dense deposit extending from the origin to the alpha ${ }_{2}$-globulin front (Fig. 9B). The beta-lipoprotein was not discernible as a separate band. In these cases the cholesterol was distributed throughout this zone although it was strongest in the beta-globulin position. One of these patients was treated first with intravenous heparin $(9,000$ units twice weekly) for 11 weeks, but this had little effect either on the serum lipid pattern or on the xanthomata. He was then put on a low-fat diet and after four weeks his condition began to improve, and the serum cholesterol to fall. Subsequently his intake of both fat and carbohydrate was restricted (he was still overweight) and further improvement occurred.

A comparison of the lipid analyses of the two sera shown in Figs. 9A and B is given below:-

\begin{tabular}{|c|c|c|}
\hline & $\begin{array}{c}\text { A. Hyper- } \\
\text { cholesterolaemia }\end{array}$ & $\begin{array}{l}\text { B. Hyper- } \\
\text { lipaemia }\end{array}$ \\
\hline 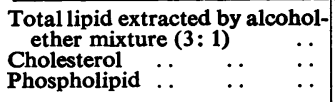 & $\begin{array}{r}2.0 \mathrm{~g} \cdot / 100 \mathrm{ml} \\
560 \mathrm{mg} . / 100 \mathrm{ml} \\
310 \quad "\end{array}$ & $\begin{array}{l}4 \cdot 2 \mathrm{~g} \cdot / 100 \mathrm{ml} . \\
580 \mathrm{mg} \cdot / 100 \mathrm{ml} . \\
550 \quad "\end{array}$ \\
\hline
\end{tabular}

On one occasion B's serum showed a total lipid of $5.5 \mathrm{~g} . / 100 \mathrm{ml}$.

We have found two cases of xanthomatosis which appeared to be a combination of these two conditions, with high cholesterol and moderately milky serum.

Jaundice and Cirrhosis. - In obstructive jaundice and in infective hepatitis both components of the alpha-lipid zone are reduced, and in severe cases

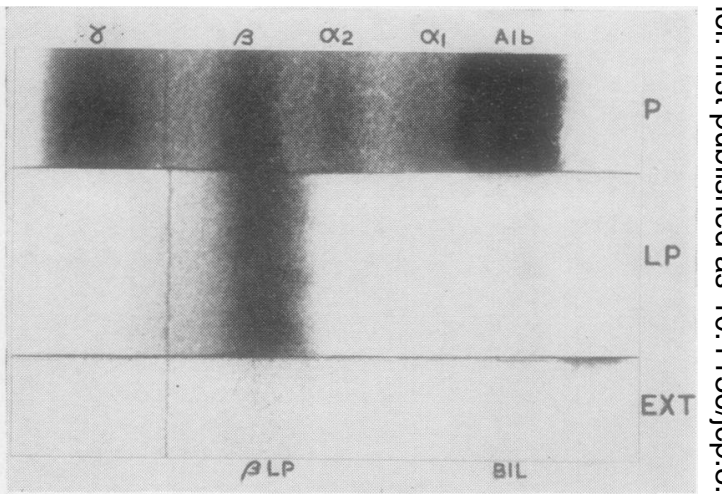

FIG. 10.-Infective hepatitis. The bilirubin strip is yellow and could not be reproduced in the photograph.

disappear altogether, while the beta-lipoprotein may be increased (Fig. 10). The serum lipid pattern of one patient was followed during the course of a $\overrightarrow{3}$ severe and prolonged attack of infective hepatitis; the alpha-lipid bands disappeared during the severe stage of the disease, but returned during recovery. The main findings are summarized in Table $\mathrm{I}$. The

TABLE I

MAIN FINDINGS IN JAUNDICE AND CIRRHOSIS

\begin{tabular}{|c|c|c|c|}
\hline & $\begin{array}{c}\text { Weeks } \\
\text { after } \\
\text { Onset of } \\
\text { Jaundice }\end{array}$ & $\begin{array}{c}\text { Serum } \\
\text { Bilirubin } \\
\text { (mg./100 ml.) }\end{array}$ & $\begin{array}{l}\text { Lipalbumin } \\
\text { and Alpha- } \\
\text { lipoprotein } \\
\text { Bands }\end{array}$ \\
\hline $\begin{array}{l}\text { Early phase } \\
\text { At height of illness } \\
\text { During recovery } \\
\text { After }\end{array}$ & $\begin{array}{l}3 \text { weeks } \\
10 " ~ \\
21 " ” \\
29\end{array}$ & $\begin{array}{c}15 \\
24 \\
1.6 \\
0.6\end{array}$ & $\begin{array}{l}\text { Both present } \\
\text { " absent } \\
\text { " present }\end{array}$ \\
\hline
\end{tabular}

findings in cirrhosis are less consistent; the lipalbumin is frequently absent, but the alpha-lipoprotein is present in most cases (Fig. 11).

Coronary Thrombosis and Peripheral Arteriosclerosis.-An increased pre-beta-lipid has been found in a high proportion of cases of coronary $\frac{D}{O}$ thrombosis; a survey of these cases is now in progress and the preliminary findings suggest that the pre- $N$ beta-lipid may increase after infarction. The prebeta-lipid is a less constant finding in peripheral arteriosclerosis.

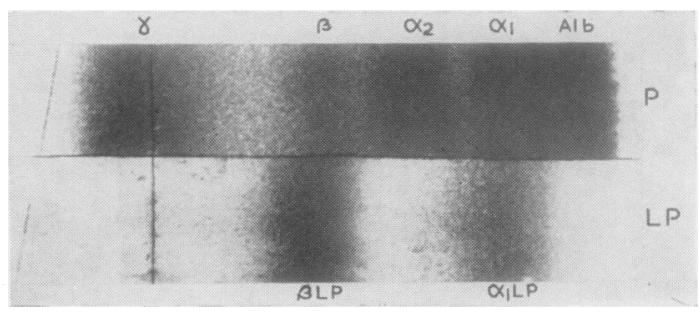

FIG. 11.-Cirrhosis. 
Effect of Intravenous Heparin.-Injection of heparin produces a marked but transient change in the lipid pattern, but has little effect on the protein pattern (Dangerfield and Smith, 1955). In serum taken 20 minutes after injection the beta-lipoprotein is found to be accelerated into the alpha ${ }_{2}$-globulin region (Fig. 12B) and the fat deposits in the trail are slightly diminished. The alpha-lipoprotein is displaced forward, apparently running ahead of the lipalbumin, and a corresponding band, staining very faintly for protein, appears ahead of the albumin but cannot be seen in the photograph. The first patients were given 15,000 or 12,000 international units, but in later cases it was found that 12,000 I.U. produced the same effects. With smaller doses the alpha-lipoprotein is not always accelerated. We have found this acceleration in as short a time as five minutes after injection, but our standard procedure was to take blood 20 minutes after injection; by 45 minutes the effect is less marked, and by two and a half hours the pattern has returned to normal.

Incubation of serum with 10 I.U. heparin per millilitre, which is approximately twice the concentration expected from the injected dose, does not change the lipid pattern. On the other hand, incubation with a small proportion (1 in 10) of plasma taken from patients 20 minutes after receiving intravenous heparin produced acceleration of the beta-lipid (cf., Comfort, 1953). This accelerating factor appears to be stable when the serum is stored for a few days at $4^{\circ} \mathrm{C}$., or for some weeks frozen at $-10^{\circ} \mathrm{C}$.

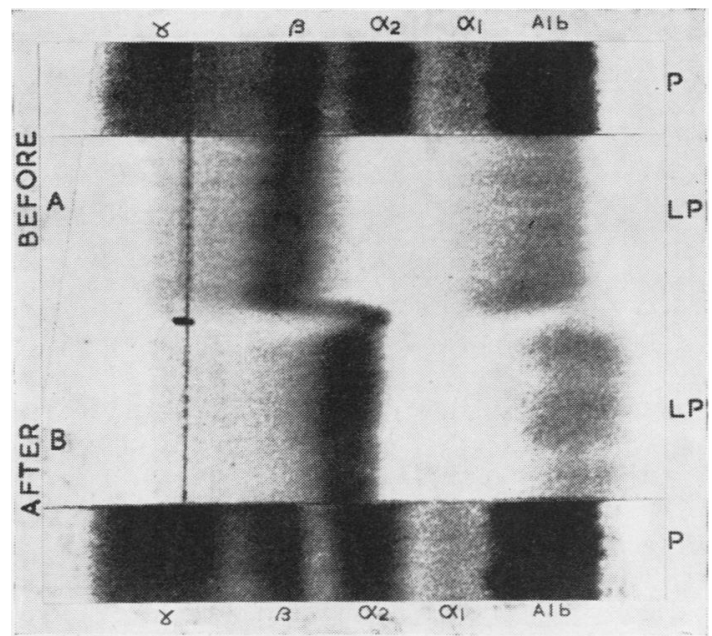

FIG. 12.-Heparin: A. Before intravenous heparin. B. After intravenous heparin.

\section{Discussion}

In this paper we have described the patterns obtained when electrophoretic strips are stained with sudan black. For the sake of simplicity the black-staining components have been referred to as lipids or lipoproteins, but in fact we have not attempted to differentiate between free lipids, lipoprotein and lipo-polypeptide complexes, and substances not generally classed as lipids which have an affinity for sudan black. The alpha- and betalipoproteins are already well established in the literature; the other components we prefer to describe merely as lipids until more detailed information on their structure is available.

The affinity of various lipids for sudan black in $55 \%$ ethanol has been tested; olive oil, cholesterol oleate, and animal fats such as lard and mutton fat are intensely stained; cholesterol stearate and lecithin are moderately deeply stained, while free cholesterol and oleic acid give only a faint coloration. It is possible that non-lipid substances have a weak affinity for this stain and that high concentrations of protein, albumin in normal serum, gamma-globulin in cirrhosis and myelomatosis, or alpha ${ }_{2}$-globulin in nephrosis give rise to faint bands. In this connexion it is particularly difficult to assess the significance of the lipalbumin band. A sample of human serum mercaptalbumin prepared from the five times recrystallized mercuric dimer was found to stain faintly with sudan black (cf., Swahn). On the other hand several sera with a normal or almost normal albumin concentration, and apparently no jaundice, showed no trace of lipalbumin, while certain body fluids and nephrotic urines with a large amount of protein showed no staining corresponding with the protein bands. The evidence is thus conflicting; if there is a lipid component associated with albumin, it appears to be very resistant to chemical separation, whereas if the protein itself is taking up the dye its affinity must be changed in certain pathological conditions. Until we have more evidence we propose using the term "lipalbumin" for the sudan-staining band corresponding with albumin, but do not wish to imply a true lipoprotein nature for it.

Comparison of serum taken before and after a fatty meal suggests that the lipids at the origin are probably neutral fat droplets deposited during application to the paper. The diffuse staining in the trail may be due to the deposition of lipid articles at different times during electrophoresis, or alternatively due to particles of various sizes migrating with a wide range of mobility.

The beta-lipoprotein has frequently been described in the literature, and occurs as a sharply defined 
band in almost all the sera that we have examined. It is consistently the densest band, contains nearly all the cholesterol, has a high phospholipid content, and is largely extracted by alcohol.

The pre-beta-lipid is a less constant finding; it could be argued that it is the front of the neutral fat trail, and that the beta-lipoprotein is superimposed on the fat, dividing it into two parts. Against this view is the fact that the trail is almost completely extracted by ethanol, whereas the pre-beta-lipid is only partially extracted in some cases, and apparently not at all in others, particularly in nephrosis. The splitting of the alpha-lipid into two or three components is in agreement with the findings of Kunkel and Slater when they used a buffer of ionic strength 0.05 . The separate bands are more clearly differentiated after alcohol extraction. In the unextracted strips the bands can be seen most clearly separated when all components are small; for instance, in cases of moderately severe nephrosis or liver disease. Sometimes only one alpha-lipid is discernible and this is usually the alpha-lipoprotein, but in three cases the lipalbumin was the only alpha component present.

The differential extraction of lipid from the strips by ethanol was unexpected, and we do not yet know what determines the solubility of different components. Virtually all the fat and cholesterol, and the bulk of the phospholipid, is removed from the beta-lipid zone, but only a small proportion of the phospholipid is removed from the alpha-lipid zone. The difference might be due to less soluble phospholipid components, to a different degree of unsaturation of the fatty acid esters, or to a firmer type of protein-lipid linkage.

Our findings on the distribution of cholesterol do not entirely agree with other reports in the literature. The amount of cholesterol found by various workers in alpha- and beta-lipoproteins separated by ethanol fractionation from human plasma pools is summarized by Oncley and Gurd (1953). All cholesterol recovered from Cohn's fractions I, II and III has been assigned to the betalipoprotein and that recovered from fractions IV, $\mathrm{V}$, and VI to the alpha-lipoprotein. The figures for alpha-lipoprotein vary from 35 to $64 \mathrm{mg} . / 100 \mathrm{ml}$., and for beta-lipoprotein from 132 to $193 \mathrm{mg} . / 100$ $\mathrm{ml}$. with means of approximately 55 and $155 \mathrm{mg} . \%$. Preliminary experiments in which we have cut out the fractions and extracted the cholesterol have given the same alpha/beta ratio of $1 / 3$, a result which disagrees with that found when the Liebermann reaction is done directly on the paper. In one experiment three strips were run with $0.05,0.1$, and $0.2 \mathrm{ml}$. serum, respectively, and treated simultaneously with the cholesterol reagent. The coloration given by the alpha-lipoprotein from: $0.2 \mathrm{ml}$. of serum was less than that given by the्ञ beta-lipoprotein from $0.05 \mathrm{ml}$. of serum, thus suggesting a ratio less than $1: 4$. This discrepances may be due to the high proportion of protein in the alpha-region interfering with the reaction.

Radioactive phosphorus is distributed throughout the strip in proportion to the total lipid. This is inf good agreement with the chemical determination op phospholipid by Kunkel and Slater, and suggests $\overrightarrow{.}$ that it is an essential part of all lipid components ${ }_{\rho}^{\omega}$ including the neutral fat droplets.

In all the pathological conditions investigated ou results are in general agreement with the findings of earlier workers, both by electrophoresis (Swahn $\overrightarrow{\tilde{\omega}}$ 1952; Kunkel and Slater, 1952) and by chemica N studies on separated plasma fractions (Barr, Russ, and Eder, 1953; Lever and Hurley, 1953). There are, however, a few minor differences; for instance in nephrosis Kunkel and Slater found a large lipid peak in the alpha ${ }_{2}$-globulin region but beta-lipo-o protein was absent. We have examined mores than 30 cases of nephrosis and find both beta-lipoprotein and pre-beta-lipid bands to be increased. The main variation is in the position of the pre-betalipid front.

The resolution of the lipids into more discrete⿳亠口冋 components should eventually help in interpretation, $\stackrel{\varrho}{\Rightarrow}$ and the appearance of a component characteristico응 of a pathological condition, in particular the prebeta-lipid in nephrosis, should prove of more value than the measurement of the overall increase in fats in certain groups of fractions.

The three cases of hyperlipaemia that we havestudied are remarkable in that the beta-lipoprotein. is not much darker than the rest of the pattern, buto is submerged in the heavy lipid staining, while the cholesterol, instead of being confined to the beta-음 lipoprotein, is distributed more or less uniformly throughout the beta-zone, with slightly strongero. staining at the origin. Examination of the lipid patterns of patients with xanthomatosis will probablyo prove to be of considerable assistance in following $\tilde{O}^{-}$ the progress of individual cases, and may possibly N help in elucidating the nature of the disease. It is tempting to speculate that deficient formation of beta-lipoprotein may be a fundamental feature of essential hyperlipaemia.

Much work has been done on the relationship between serum lipid and lipoprotein changes and the incidence of coronary thrombosis, atherosclerosis, $\stackrel{\mathbb{Q}}{\stackrel{\mathrm{Q}}{\Omega}}$ and malignant hypertension; ultracentrifuge studies $\mathbb{Q}$ have been extensively pursued. The lipoproteins are of low density and "sediment" upwards if the 
density of the serum is increased by the addition of strong salt solutions. Jones, Gofman, Lindgren, Lyon, Graham, Strisower, and Nichols (1951), working mainly at a density of 1.063 , have found increased amounts of several lipoprotein fractions, particularly those they designate $S_{f} \quad 12-20$ and $S_{\mathrm{f}}$ 30-100. Lewis and Page (1953), using a density of 1.21 , have also found an increase in low-density components in malignant hypertension and in nephrosis, but they do not believe that it is justifiable to attribute atherosclerosis to any one of these components. They have studied some of their ultracentrifuge fractions in the Tiselius apparatus and have compared the ultracentrifuge and electrophoretic results. This correlation of ultracentrifuge and electrophoretic results is important and we are endeavouring to prepare the components that we have described in the ultracentrifuge.

In agreement with Lewis and Page we have not been able to demonstrate any change in the pattern that is really characteristic of the atheroma group of conditions; the pre-beta-lipid occurs more frequently than in normals, but it is by no means a constant finding, and it is probable that a quantitative method of assessment will be required to give any useful information. A combined ultracentrifuge and electrophoretic study may well be more profitable than either investigation alone.

In nephrosis the increased beta-lipids and decreased alpha-lipids is easily apparent and convincing; the difficulty here is to understand the significance of the effect. It is possible that for following the progress of individual cases the lipid pattern may be of greater value than the protein pattern, for it is our impression that the protein changes follow rather than precede the clinical changes.

These changes in the lipid pattern give an added interest to lipoproteins. In spite of the relative abundance of beta-lipoprotein in serum its origin, fate, and function are largely a matter of surmise. It is hoped that further work along the present lines may give some information either of theoretical or clinical value.

\section{Summary}

Methods for preparing and staining electrophoresis strips for protein, fat, and cholesterol are described, and the relative positions of these components in normal and pathological sera are shown.

The distribution of phospholipid has been determined by autoradiography of patterns from patients after treatment with ${ }^{3:}:$.

A characteristic abnormal band, which is insoluble in absolute alcohol, is found in nephrosis. In many, but not all, cases of coronary thrombosis there is a similar band.

Intravenous heparin increases the mobility of the lipoproteins.

Photographs are shown of the lipoprotein patterns found in various conditions.

We wish to thank Dr. Iain MacDougall and Mr. J. S. Ajayi for assistance in the initial stages of this work, and Professor Blacklock for advice in preparing this paper.

\section{REFERENCES}

Barr, D. P., Russ, E. M., and Eder, H. A. (1953). In Blood Cells and Plasma Proteins, p. 382, edited by J. L. Tullis. Academic Press, New York.

Comfort, A. (1953). Biochem. J., 54, xxiii.

Dangerfield, W. G., and Smith, Elspeth B. (1955). Biochem. J., 59, vi.

Flynn, F. V., and de Mayo, P. (1951). Lancet, 2, 235.

Hack, M. H. (1953). Biochem. J., 54, 602.

Jones, H. B., Gofman, J. W., Lindgren, F. T., Lyon, T. P., Graham, D. M., Strisower, B., and Nichols, A. V. (1951). Amer. J. Med., 11, 358 .

Kunkel, H. G., and Slater,' R. J. (1952). J. clin. Invest., 31, 677.

Lever, W. F., and Hurley, A. (1953). In Blood Cells and Plasma Proteins, p. 392.

Lewis, Lena A., and Page, I. H. (1953). Circulation, 7, 707.

Oncley, J. L., and Gurd, F. R. N. (1953). In Blood Cells and Plasma Proteins, p. 337.

- and Melin, M. (1950). J. Amer. chem. Soc., 72, 458.

Swahn, B. (1952). Scand. J. clin. Lab. Invest., 4, 98. 